Discussion

Papers

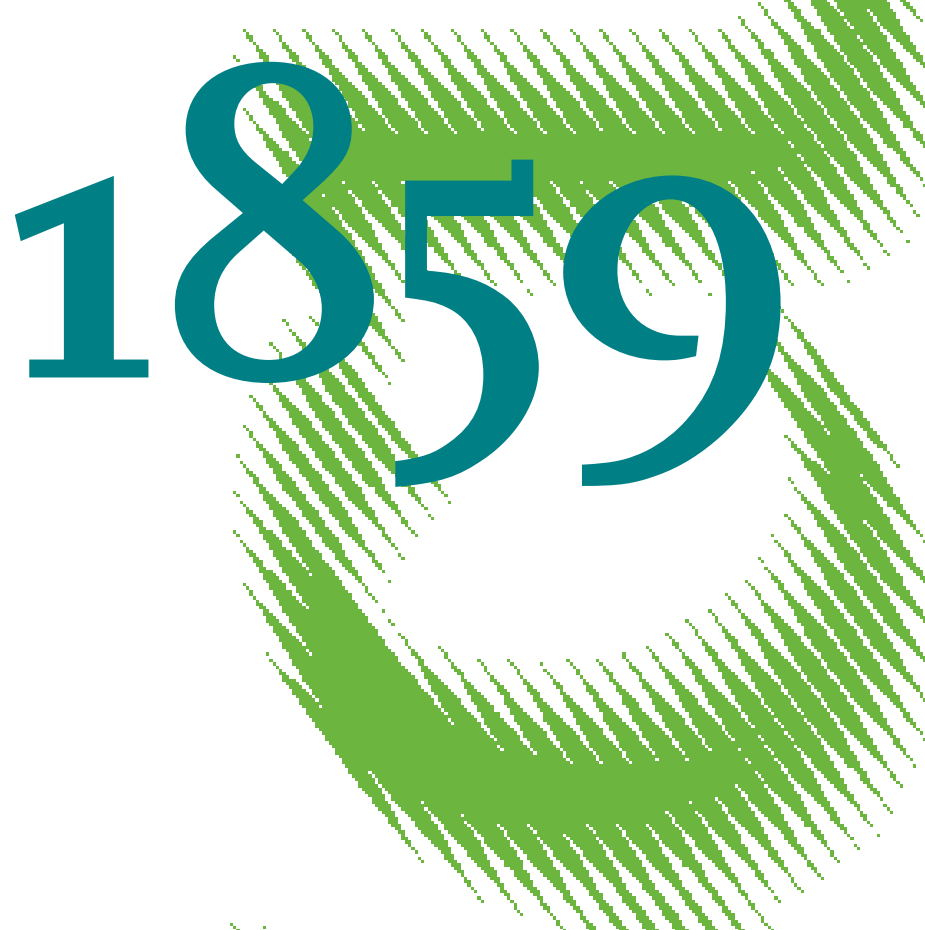

Time-Consistent Carbon Pricing: The Role of Carbon Contracts for Differences 
Opinions expressed in this paper are those of the author(s) and do not necessarily reflect views of the institute.

IMPRESSUM

(C) DIW Berlin, 2020

DIW Berlin

German Institute for Economic Research

Mohrenstr. 58

10117 Berlin

Tel. +49 (30) $89789-0$

Fax +49 (30) $89789-200$

http://www.diw.de

ISSN electronic edition 1619-4535

Papers can be downloaded free of charge from the DIW Berlin website:

http://www.diw.de/discussionpapers

Discussion Papers of DIW Berlin are indexed in RePEc and SSRN:

http://ideas.repec.org/s/diw/diwwpp.html

http://www.ssrn.com/link/DIW-Berlin-German-Inst-Econ-Res.html 


\title{
Time-consistent carbon pricing: the role of carbon contracts for differences*
}

\author{
Olga Chiappinelli ${ }^{\dagger}$ and Karsten NeuhofF ${ }^{\ddagger}$ \\ A previous version of this paper was titled: \\ "Time-consistent carbon pricing"
}

\begin{abstract}
Carbon pricing decisions by governments are prone to time-inconsistency, which causes the private sector to underinvest in emission-reducing technologies. We show that incentives for decarbonization can be improved if complementing carbon pricing with carbon contracts for differences, where the government commits to pay a fixed carbon price level to the investors. We derive conditions under which the government is willing to "tie its hands" with the contracts.
\end{abstract}

Keywords: Carbon pricing; Time-inconsistency; Green technology; Climate policy; Carbon contracts.

JEL Classification: C73, L51, O31, Q58.

*We thank Joern Richstein, Nils May, Toke Aidt, Cameron Hepburn, Pio Baake, Carmen Arguedas, Michael Finus, Robert Schmidt, Emmanuelle Auriol as well as seminar participants at Autonoma University Madrid and conference participants at 1st Workshop on Economic Theories and Low-Carbon Transformation Policies, FSR 2017 Climate Annual Conference, WCERE 2018, EEA-WinE Retreat, EARIE 2018 and Berlin-Bavaria Energy Workshop 2019 for useful comments. We are grateful for financial support from the German Federal Ministry for Economic Affairs and Energy (researcg grant SEEE, funding number 03MAP316) and the Mistra Carbon Exit Research Program. Declaration of interest: none.

${ }^{\dagger}$ DIW Berlin. E-mail: ochiappinelli@diw.de.

${ }^{\ddagger}$ DIW Berlin. E-mail: KNeuhoff@diw.de. 


\section{Introduction}

In order to address the global warming challenge and move toward a carbon-neutral economy, ambitious decarbonization targets have been set in the recent years (e.g., Paris agreement 2015, EU 2020 climate and energy package).

It is broadly agreed that to achieve such targets, substantial investment in low-carbon technologies and practices in the emission intensive sectors (e.g., heavy industries, power sector) is urgently needed (see e.g., IPCC (2018)).

To induce the private sector to invest in low-carbon options, governments need to put regulations and policies in place that ensure a secure stream of revenues for the investments, thereby offsetting the usually not internalized environmental externalities (see e.g., Stern (2007)). One crucial piece of policy in this respect is the introduction of a carbon price, by means of a carbon tax (see e.g., Pigou (1920) or an emission permit system (Coase (1960)). A high enough, and stable, carbon price can improve the economic viability of more costly green technologies relative to cheaper conventional ones, therefore providing the private sector with the appropriate incentives to invest in deep emission abatement and ensuring the profitability of the low-carbon transition.

However, existing experience with carbon pricing schemes is that the carbon price levels are too low to trigger any meaningful investment, thereby hindering the realization of mitigation potentials. One important reason for weak carbon pricing is because of timeinconsistency issues: governments and regulators have an incentive to create expectations of a high carbon price but ex-post implement less stringent carbon pricing policies (see e.g., Helm et al. (2003) and Brunner et al. (2012)).

There are a number of episodes in recent history showing that time-inconsistent behavior in the context of carbon pricing and climate policies is frequent. For example, in the summer of 2000, the UK government froze the automated increase of gasoline taxes - which had been decided and announced as part of its 2000 budget plan in March - in response to big protests by truck drivers across the UK, which had caused severe disruption of fuel supplies $1^{1}$ In December 2018 the French government decided to put on hold a previously announced fuel tax increase, including a carbon component; these were among the policies that triggered demonstrations across the country starting in November 2018 (so called "Yellow vest movement") $!^{2}$

\footnotetext{
${ }^{1}$ See e.g., "Chancellor freezes fuel in cautious pre-Budget". The Daily Telegraph. Telegraph News and Media Limited. 8 November 2000.

${ }^{2}$ See e.g., "Macron Blinks as Yellow-Vests Protest Forces Fuel-Tax Climbdown". Bloomberg. 4 December 2018.
} 
These examples suggest that time-inconsistent carbon pricing choices by governments are often induced by welfare concerns. The climate goal and consumer welfare goal in the political and regulatory agendas are conflicting: carbon pricing creates incentives for decarbonization but implies a price increase of basic polluting goods with (short-term) inelastic demand (e.g., electricity, fuel) that negatively affect consumer welfare. To the extent that regulators and politicians pursue consumer welfare, they have the motive to engage in time-inconsistent behavior when setting climate policies.

Regulators and politicians also have the scope for time-inconsistent behavior. Carbon pricing announcements and decisions are not enforceable, while low-carbon investments are irreversible and specific to climate policy. Therefore, governments have an incentive to create expectations of a relatively high carbon price (e.g., announcing a reduction in the number of permits or the imposition of a high carbon tax) in order to induce the private sector to invest in abatement technologies, hence achieving the goal of reducing emissions; then, after investments have been made, governments have an incentive to $e x-$ post re-optimize the policy by lowering the carbon price in order to avoid the negative impact on consumer welfare.

The consequence of this credibility issue is a typical hold-up problem (Williamson (1975)), where firms, as rational agents, anticipate the risk of rent-expropriation due to such ex-post opportunistic behavior on the side of the government and either do not invest or underinvest in low-carbon solutions, such that no relevant emission reduction is realized and the economy is stuck in a high-emission scenario.

In this paper we show that carbon pricing is affected by time-inconsistency and we investigate carbon contracts for differences as a solution to address the consequent hold-up problem and to restore the incentive for the private sector to invest in abatement.

Carbon contracts for differences are contracts between the government and a firm that pay out the difference between the general current carbon price and a fixed agreed guaranteed price, so-called "strike price" per tonne of emission reduction delivered by the firm through a low-carbon project. As the government commits, through the contracts, to a payment whenever the carbon price is lower than the strike price, such carbon contracts introduce a financial cost, for the government, of setting low carbon prices. Carbon contracts for differences are enforced by private law, meaning that the government cannot (easily) unsettle or change them once they are set. Therefore, as long as the government is willing to "tie its hands" by issuing the contracts, the latter can work as a commitment device in presence of time-inconsistency issues. Carbon contracts for differences are now in the design stage in a number of countries (e.g., Germany, the Netherlands) as a policy 
proposal for the decarbonization of heavy industries, which makes it a good point in time to ask questions about their performance.$^{3}$

In this paper, we consider a general-function game of carbon regulation between a government with mixed preferences that sets a carbon price and a representative firm that chooses a level of investment in an emission-reducing technology.

As a first result, we find that, in the absence of commitment, the government sets a lower level of carbon price relative to the commitment benchmark and the firm underinvests in the clean technology. This is because, when investment is made, and, therefore, emission abatement achieved, carbon pricing only triggers emissions reduction through consumption cuts. Therefore it has a lower benefit than under commitment when the firm also responds to higher price by increasing its abatement effort. Further, the larger the investment, and, therefore, the larger its decarbonization benefit, the lower the optimal price, as the government can afford to lower the burden on consumers. On the other hand, the firm takes into account that investment is going to put downward pressure on carbon price levels, therefore reducing the profitability of abatement, such that - in response to such expropriation risk - it withholds investment relative to the commitment benchmark.

We then show that, by complementing carbon pricing with carbon contracts for differences, a welfare-improving price-investment equilibrium can be achieved. On one hand, low-carbon investment by the firm is now remunerated through the contracts, so, provided the strike price is not too low, the firm chooses a higher level of investment relative to the case with no contracts. In addition, the level of investment approaches the commitment benchmark level when the strike price approaches the commitment benchmark carbon price level. As for the equilibrium choice of carbon price by the goverment, this is also higher than in the case without contracts, provided the strike price is large enough. Interestingly, the equilibrium carbon price under the contracts is non-monotonic in the strike price. This is because an increase in the strike price has two opposite effects on carbon pricing. On the one hand, it increases investment and, thus, decarbonization benefits, which, as in the case without contracts, puts downward pressure on the optimal carbon price (even though at a lower rate than before). On the other hand, it increases the cost of remunerating investment through the contracts, which puts upward pressure on the optimal carbon price, as the government wants to reduce the payment due to the firm. While for low enough levels of the strike price, the negative "investment effect" outweighs

\footnotetext{
${ }^{3}$ See e.g. Richstein (2017), Neuhoff et al. (2019). Similar contracts for difference have been recently introduced for the power sector in the United Kingdom and are in the policy design stage in other countries (see e.g. May et al (2018)).
} 
the positive "financial effect", the opposite is true for large enough levels of the strike price.

We then consider the problem of the adoption of the contracts by the government and show that if the strike price is exogenous, the government finds it optimal to issue the contracts as long as the strike price is not too high, i.e., it is not too expensive to remunerate investment through the contracts. If the government has discretion over the strike price, it chooses a level such that it finds it always optimal to "tie its hands" with the contracts. Even if the level is below the carbon price level of the commitment benchmark, so that the commitment benchmark level of investment is never reached, a welfare improvement relative to the case with no contracts is always ensured.

Thus, our analysis provides evidence that carbon contracts for differences can act as a credible commitment device, thereby improving on the problem of time inconsistency in carbon pricing decisions. While the existing policy proposal envisages providing regulatory commitment to individual investors with project-based carbon contracts for differences, the contracts can also help to mitigate the time inconsistency problem for firms in the market that are not covered by the contracts, as the latter weaken the incentives for governments to reduce the overall carbon price level.

Our work relates to the literature on time-inconsistency, credibility, and opportunism issues in environmental regulation and climate policy.

The time inconsistency problem is not new to the economic literature and not specific to climate policy, but common to many regulatory settings, such as monetary policy (see e.g., Barro (1983) and Kydland and Prescott (1977)) and rate-of-return regulation (see e.g, Laffont and Tirole (1993)). The problem is extensively researched in the specific context of climate policy and environmental regulation (see Brunner et al. (2012) for a comprehensive literature review). Two main sub-strands can be individuated. The former considers the credibility problem as arising in the strategic interaction between different countries and mostly considers free-riding issues in global carbon pricing and international climate negotiations (see e.g., Harstad and Eskeland (2010), Finus and Pintassilgo (2013) and Battaglini and Harstad (2016)).

The latter, to which this work contributes, individuates the main source of opportunistic behavior in the strategic relationship between regulators and firms in a single jurisdiction, with different contributions focusing on different specific sources of the problem and suggesting different solutions. Like this paper, some works consider mixed political preferences as the origin of time inconsistency. The papers closest to ours are Laffont and Tirole (1996)) and Helm et al. (2004). The former considers a Stackelberg game between a 
government that sets a carbon price and an innovator that realizes a clean technology with some probability and shows that advance allowances and options to pollute can improve on the expropriation problem. The latter considers a (specific-function) game between a government that sets a carbon tax and firms that can abate emissions by increasing production costs. It then shows that the commitment benchmark can be achieved by delegating environmental regulation to an independent environmental agency. Two other related papers that focus on time inconsistency of energy taxation are Marsiliani and Renström (2000) and Kalkuhl et al. (2020). The former shows that tax-earmarking can be a partial solution to the problem, while the latter that time inconsistency originates from the lobbying power of firms and fiscal considerations, and that the two only consistent tax policies are either no tax or a prohibitively high one.

Our main contribution relative to these papers is to consider the role of carbon contracts for differences as a solution to the time-inconsistency problem. In general, despite their potential - also in relation to other policies $4^{4}$ - carbon contracts are so far largely neglected by the literature. The only economic analyses we are aware of are provided by the aforementioned Laffont and Tirole (1996)), which provides a marginal investigation of carbon put-options, and Richstein (2017), which focuses on the optimal combination of carbon contracts and upfront funding for lowering the policy cost for innovation finance. Ismer and Neuhoff (2009) and Helm and Hepburn (2005) provide non-technical analyses of the legal and practical implementation.

Other papers in the literature focus on different sources of time-inconsistency, namely myopia and political alternation (e.g., Ulph and Ulph (2013)), changing or uncertain marginal abatement cost, or damage from emissions (e.g., Biglaiser et al. (1995), Gersbach and Glazer (1999), Jacob and Brunner (1977) ), hyperbolic discounting (e.g., Gerlagh and Liski (2017)); as well as different solutions such as investment subsidies (e.g., Abrego and Perroni (2002), Golombeck et al. (2010), Montero (2011) or adjustment rules Jacob and Brunner (1977) ). Finally, May and Chiappinelli (2018) show, in the context of renewableenergy support regulation, that in absence of complementary policies, reputation effects built through a repeated relationship can bring some improvement to the commitment problem.

The structure of the paper is as follows. In Section 2 we present a game of carbon regu-

\footnotetext{
${ }^{4}$ For example, carbon contracts can be auctioned and can be technology blind, avoiding some of the main limitations of R\&D subsidies, where governments are forced to "pick winners". Further, while subsidies provide little incentive for cost-efficiency and completion of projects, carbon contracts for differences remunerate firms per volume of emission reduction, thereby creating strong incentives (see e.g., Helm and Hepburn (2005), Neuhoff et al. (2019)).
} 
lation. In Section 3 we characterize the solutions of the regulation game with stand-alone carbon pricing. In Section 4 we consider the case where carbon price is complemented with carbon contracts for differences. In Section 5 we study the problem of the adoption of the contracts by the government. In Section 6 we briefly conclude. All proofs are gathered in the Appendix.

\section{The model: a carbon regulation game}

Consider the following simple setting of carbon regulation. There is a continuum of consumers with (direct) demand for a polluting good (e.g., electricity) $Q\left(p_{G}\right)$ where $p_{G} \geq 0$ is the good price, such that $\forall p_{G} \geq 0, Q^{\prime}<0, Q^{\prime \prime} \geq 0$, and $Q^{\prime \prime \prime} \leq 0$. To convey the idea that consumers cannot easily cut the consumption of an essential good, demand is assumed to be inelastic: $\eta\left(p_{G}\right)=-\frac{Q^{\prime}\left(p_{G}\right) p_{G}}{Q\left(p_{G}\right)}<1$.

The representative producer can produce one unit of the good at cost $c \geq 0$. The production of one unit generates one unit of pollution, which, in turn, creates social damage $d>0$.

The firm can reduce emissions by investing in a cleaner technology: a level of investment $x \in[0,1]$ reduces emissions to $(1-x)$ at cost $C(x)$, with i) $C(0)=0$; ii) $C^{\prime}(0)=0$; iii) $\forall x \in(0,1) C^{\prime}>0, C^{\prime \prime}>0, C^{\prime \prime \prime}>0$; and iv) $\lim _{x \rightarrow 1} C^{\prime}(x)=+\infty 5$

The firm is subject to a carbon price $p$, set by the government, such that it must pay for unabated emissions $p(1-x)$.

The product market is assumed to be competitive and the following simplifying assumptions hold:

- The dirty technology is price setter and there is full carbon price pass through, such that the carbon price is fully charged to consumers. This results in a market price of the good of $p_{G}=c+p$.

- The number of firms in the market is such that production covers all demand at that price.

The firm gets revenue $(c+p)$ by selling the good to consumers, incurs production costs $c$, has to pay $p(1-x)$ for unabated emissions plus investment costs $C(x)$. Therefore, the profit function of the firm is as follows:

\footnotetext{
${ }^{5}$ Assumption iv) ensures that the firm never invests to the level than allows to completely eliminate emissions.
} 


$$
\Pi=(c+p)-c-p(1-x)-C(x)
$$

which reduces to

$$
\Pi=x p-C(x)
$$

In this model, the benefit of investment for the firm consists of savings in carbon costs. ${ }^{6}$ As the carbon cost for an abating technology increases less then proportionally with respect to the carbon price, the profit from abatement increases with the carbon price. Clearly, by setting the carbon price, the government determines the profitability of investment in abatement. In the following we adopt the normalization $c=0$, so that the product price is fully determined by the carbon price, $p_{G}=p$.

The social welfare function of the government comprises three elements:

- Gross consumers surplus $S(p)=\int_{p}^{\infty} Q(z) d z+p Q(p)$, such that i) $S^{\prime}(p)=p Q^{\prime}(p)<0$; ii) $S^{\prime \prime}(p)=Q^{\prime}(p)+p Q^{\prime \prime}(p) \leq 0$; iii) $S^{\prime \prime \prime}(p)=2 Q^{\prime \prime}(p)+p Q^{\prime \prime \prime}(p) \geq 0$; and iv) $\lim _{p \rightarrow \infty} S(p)=0.7$

- Damage from emissions $D(p)=d(1-x) Q(p)$

- Public revenues from carbon pricing $R(p)=p(1-x) Q(p)$,

Therefore, the government chooses a carbon price level $p$ that maximizes 8

$$
W=S(p)-D(p)+R(p)
$$

Notice that an increase in price on one hand reduces consumer surplus but also the damage from emissions, while simultaneously increasing revenues (because of inelastic

\footnotetext{
${ }^{6}$ Given the assumptions, in this model the firm is not punished for not abating, rather it is rewarded for abating.

${ }^{7}$ Notice that assumption i) follows from the assumptions on the shape of the demand function. Assumptions i) - iv), as well as the choice to use gross consumer surplus, guarantee the strict concavity of the social welfare function and regularity of reaction functions. Results would not change qualitatively by using net consumer surplus rather than gross consumer surplus.

${ }^{8}$ Similar to Helm et al. (2004), we do not include firm profits in the social welfare function. As adding the profits of the firm would weaken the hold-up issue, our analysis describes the worst-case scenario of time inconsistency and our results should be given a lower-bound interpretation. In addition, we focus on the domestic dimension of carbon pricing decisions, where the main trade-off is between the climate goal and consumer welfare protection. The perspective of the firm is more crucial when looking at the international dimension of carbon price setting, where the main trade-off for the government is between achieving decarbonization and protecting the competitiveness of national companies in international markets.
} 
demand). Therefore, there is a clear trade-off underlying carbon pricing decisions by the government.

In addition, notice that while for a given level of investment, a change in the carbon price impacts on emissions only through consumption levels, if the firm's investment is not fixed but responds endogenously to the carbon price, a change in carbon price induces firms to change the level of abatement. Therefore, while the impact on consumer surplus is the same, damage and revenues are more responsive to a change in carbon price.

In the following we also assume that the decarbonization marginal benefit of investment is never below its marginal cost in terms of missed revenues: $d \geq p 9^{9}$ In addition, we assume no discounting between the stages of the sequential move game. Finally, there is complete information in the model, with both the government and the firm being riskneutral.

Depending on whether the government can commit or not to the announced carbon price, two different Stackelberg games between the firm and the regulator arise. In presence of commitment, the government (leader) announces and commits to a carbon price level and the firm (follower) chooses its investment level. In absence of commitment, the firm (leader) chooses an investment level and the government (follower) chooses a carbon price.

In the following, we derive the SPNE of the two games by backward induction.

\section{Regulatory solutions with stand-alone carbon pric- ing}

\subsection{Solution under commitment}

As a useful benchmark, we consider the case where the government can commit to the announced carbon price. In this case, by backward induction the firm chooses, in the second stage, the investment level that maximizes profits given the announced carbon price level (i.e., the firm's reaction function):

$$
x(p)=\underset{x}{\operatorname{argmax}} \quad \Pi^{c b}=x p-C(x)
$$

It is straightforward to check the following.

\footnotetext{
${ }^{9}$ In this model $d$ represents both the marginal damage of emissions and the marginal decarbonization benefit of investment.
} 
Lemma 1. The investment problem of the firm has a unique solution $x(p)$ characterized by $p=C^{\prime}(x)$ with the following properties: i) $\forall p>0, x(p)>0$; ii) $x(0)=0$; iii) $\forall p \geq 0$, $x^{\prime}(p)>0$ and $x^{\prime \prime}(p)<0$; and $\left.i v\right) \lim _{p \rightarrow \infty} x(p)=1$.

As the profits of abating increase with the carbon price, the optimal investment level of the firm increases with the price, at a decreasing rate. When the government forgoes carbon pricing, the firm optimally refrains from investment.

In the first stage, the government chooses the carbon price level that maximizes the social welfare function while accounting for the reaction function of the firm to the announced price. That is, the problem of the government is as follows:

$$
\max _{p} W^{c b}=S(p)-d Q(p)[1-x(p)]+p Q(p)[1-x(p)]
$$

The solution is characterized in the following lemma.

Lemma 2. The carbon pricing problem of the government has a unique solution $p^{c b}$ characterized by

$$
-p Q^{\prime}(p)=d\left[Q(p) x^{\prime}(p)-Q^{\prime}(p)(1-x(p))\right]+\left[Q(p)+p Q^{\prime}(p)\right](1-x(p))-p Q(p) x^{\prime}(p)
$$

In addition, $\frac{\partial p^{c b}}{\partial d}>0$.

The optimal carbon price balances the marginal cost of a carbon price increase in terms of the reduction in consumer surplus, $\left(S^{\prime}(p)\right.$, LHS of (6p) and marginal benefit (RHS of (6) ) in terms of i) the reduction of damage from emissions $\left(-D^{\prime}(p)\right)$, both from increased investment (first term in the squared brackets) and from reduced consumption (second term in the squared brackets); and ii) the impact on revenues $R^{\prime}(p)$ i.e., the increase due to demand inelasticity (second term on RHS) net of the decrease due to increase in investment (last term on RHS) ${ }^{10}$

Intuitively, the optimal price is increasing with the damage of emissions - higher pollution damage increases the marginal benefit of pricing while leaving the marginal cost unaffected. The effect translates directly to the optimal level of investment $x^{c b}=x\left(p^{c b}\right)$.

\footnotetext{
${ }^{10}$ Given assumption $d \geq p$ both the net impact of a marginal increase of investment $x^{\prime}(p) Q(p)[d-p]$ and the net impact of a marginal reduction in consumption $-(d-p) Q^{\prime}(p)(1-x(p))$, are positive.
} 


\subsection{Solution in absence of commitment}

Unlike what is assumed in the previous section, the government is typically unable to commit to its climate policy announcements. Therefore, after the firm has invested, the government is able to implement a different carbon price level than the one announced. The timing is therefore that the firm chooses a level of investment based on rational expectations about the government's behavior; thereafter, the government sets a carbon price level.

By backward induction, the government sets in the second stage a carbon price that maximizes welfare for a given level of investment (i.e., the government's reaction function):

$$
p(x)=\underset{p}{\operatorname{argmax}} \quad W^{n c}=S(p)-d Q(p)(1-x)+p Q(p)(1-x)
$$

The reaction function of the government is characterized in the following lemma:

Lemma 3. The carbon pricing problem of the government has a unique solution $p(x)$ characterized by

$$
-p Q^{\prime}(p)=-d Q^{\prime}(p)(1-x)+\left[Q(p)+p Q^{\prime}(p)\right](1-x)
$$

and such that $\forall x \in[0,1)$ : i) $p(x)>0$; ii) $p^{\prime}(x)<0$; iii) $p^{\prime \prime}(x)<0$; and iv) $\lim _{x \rightarrow 1} p(x)=$ 0 .

The optimal pricing level equalizes marginal cost in terms of consumer welfare loss (LHS of (8)) and marginal benefit in terms of emission reduction from cutting consumption (first term RHS) and revenue increase due to demand inelasticity (second term RHS). Notice, as already anticipated, that while the marginal cost of a price increase is the same, the marginal benefit is lower than under commitment, as it reduces emissions and increases revenues only through consumption levels, since investment is fixed.

In absence of commitment, the optimal carbon price level for the government is a decreasing function of the investment level. This is so because, once investment is made, and therefore emission reduction through investment achieved, the only benefit of carbon pricing is reducing emissions through consumption cuts. The larger the investment, the lower the decarbonization benefit of reducing consumption, so that the government can "afford" containing the impact on consumers by reducing the price. Furthermore, the larger the investment, the lower the benefit in terms of revenues from carbon pricing, which puts further downward pressure on the optimal price level. 
By backward induction, in the first stage, the firm chooses the investment level that maximizes its profits while taking into account the government's reaction function:

$$
\max _{x} \Pi^{n c}=x p(x)-C(x) .
$$

Lemma 4. The investment problem of the firm has a unique solution $x^{\text {nc }}$ characterized by the condition

$$
p(x)+x p^{\prime}(x)=C^{\prime}(x)
$$

The optimal investment level equalizes marginal benefit (LHS) and marginal costs (RHS). Notice that the firm takes strategically into account the effect of its choices on carbon pricing decision and, in particular, the fact that a larger investment level will trigger a reduction in carbon pricing $\left(p^{\prime}(x)<0\right)$. Therefore the firm withholds investment so as to contain the profit reduction - a typical expropriation argument (Williamson (1975)). We denote the optimal carbon price level as $p^{n c}=p\left(x^{n c}\right)$.

It is possible to show that such strategic behavior from both the firm and the government implies that both the carbon price level and the investment level are below the commitment benchmark, as summarized in the following proposition.

Proposition 1 (Regulatory solution with stand-alone carbon pricing). When the government cannot commit to carbon pricing, the government sets a lower level of carbon price $\left(p^{n c}<p^{c b}\right)$ and the firm underinvests in low-carbon technology $\left(x^{n c}<x^{c b}\right)$ relative to the commitment benchmark. This results in both the government and the firm being worse off relative to the commitment benchmark case ( $\left.W^{n c *}<W^{c b *}, \Pi^{n c *}<\Pi^{c b *}\right)$.

\section{Carbon regulation with carbon contracts for dif- ferences}

In absence of other polices that complement carbon pricing, the only possibility to improve on the negative outcome illustrated above is that the government can, over time, build its reputation for being ambitious about carbon pricing. If the government and the firm can interact on a repeated basis and if the government is enough forward looking, a superior price-investment outcome can be achieved. However, in the short term or with changing governments, improvement is impossible if carbon pricing is not complemented with other policies. 
As mentioned before, in absence of commitment, the government may be willing to "tie its hands" through policies, like institutional and contractual arrangements, that impose a cost on setting a weak climate policy, like a low carbon price. In this section, we investigate the role of carbon contracts for differences. A carbon contract for differences is a contract between the firm and the government where the firm is guaranteed a fixed price, called "strike price" $p_{s}$, for unit of emission reduction delivered with the investment. It is implemented as a contract for differences with the carbon price, meaning that $\forall p, p_{s} \geq 0$

- if the carbon price is lower than the strike price $p \leq p_{s}$, the government pays $\left(p_{s}-p\right) x$ to the firm,

- if the carbon price is higher than the strike price $p>p_{s}$, the firm pays $\left(p-p_{s}\right) x$ to the government.

Clearly, this type of contract imposes a financial cost on the government for setting a low carbon price level. Unlike the general carbon price $p$, the strike price $p_{s}$ is part of a contract. As contracts are enforced by private property law ("securitization"), the government cannot (easily) unsettle or modify them once they are set (see Brunner et al. (2012)). Thus, as long as the government is willing to issue the contracts, the latter can work as a commitment device. In the following, we derive the regulatory solution in the presence of carbon contracts for differences by considering the strike price $p_{s}$ as exogenous. In Section 5, we investigate under what conditions the government is willing to set the contracts, also considering the case when the government can optimize on $p_{s}$.

The timing of the carbon pricing game with carbon contracts for differences is as follows:

$\mathbf{t}=\mathbf{0}$ The government decides whether to issue a binding carbon contract for differences with guaranteed strike price $p_{s}$.

$\mathbf{t}=\mathbf{1}$ Firm and government sign the contract and the firm chooses investment level $x$.

$\mathbf{t}=\mathbf{2}$ The government chooses a carbon price level $p$, demand and emissions realize, and contract payments are made.

The social welfare function is now

$$
W^{c c}=S(p)-d Q(p)(1-x)+p Q(p)(1-x)-x Q(p)\left(p_{s}-p\right)
$$


The profit function for the firm (by simplifying the profits from abatement: $(p+c)-$ $\left.p(1-x)-c+x\left(p_{s}-p\right)-C(x)\right)$, is

$$
\Pi^{c c}=x p_{s}-C(x)
$$

Notice that the firm now is remunerated by the strike price only.

Like before, the government chooses the level of carbon price that maximizes welfare for a given level of investment:

Lemma 5. As long as the strike price is not too high $\left(p_{s} \leq d\right)$, the carbon pricing problem of the government has a unique solution $p^{c c}(x)$ characterized by the following condition:

$$
-p Q^{\prime}(p)=-d Q^{\prime}(p)(1-x)+(1-x)\left[Q(p)+Q^{\prime}(p) p\right]+x\left[Q(p)-Q^{\prime}(p)\left(p_{s}-p\right)\right]
$$

and such that $\forall x \in[0,1)$ : i) $p^{c c}(x)>0$; ii) $p^{c c^{\prime}}(x)<0$; iii) $p^{c c^{\prime \prime}}(x)<0$; iv) $\lim _{x \rightarrow 1} p^{c c}(x)=$ $\underline{p}^{c c}>0$; and $\left.v\right) p^{c c^{\prime}}\left(p_{s}\right) \geq 0$.

In addition, the following holds:

Lemma 6. $\forall x \in[0,1)$ : i) $p^{c c}(x) \geq p(x)$; and ii) $\left|p^{c c^{\prime}}(x)\right|<\left|p^{\prime}(x)\right|$.

The equilibrium pricing level of the government under the contracts, given the investment level of the firm $p^{c c}(x)$, balances the marginal cost in terms of consumers welfare loss (LHS (13) ) and the marginal benefit in terms of i) reduced emissions due to reduced consumption (first term RHS 13), ii) increased revenues from carbon pricing (second term RHS (13)), and iii) lower payment to or increasing payment from the firm (third term RHS (13)) .11 Notice that, unlike the case with stand-alone carbon pricing, now the firm's investment creates a financial cost for the government if the carbon price declines below the strike price $\left(p_{s} \geq p\right)$ and a financial benefit otherwise $\left(p_{s}<p\right)$. Therefore, for a given level of investment, the optimal price level is higher than in the case without contracts, as carbon pricing has an extra marginal (financial) benefit $\left(p^{c c}(x) \geq p(x)\right)$. While the optimal price still decreases with investment $\left(p^{c c^{\prime}}(x)<0\right)$, as the government can afford a lower burden on consumer welfare, it does so at a weaker pace than in the case without

\footnotetext{
${ }^{11}$ Notice that the latter is made of two components: on one hand the government needs to pay a lower price differential (resp. gets a higher price differential) per unit of emission reduction because the price is higher $(x Q(p))$ and, on the other hand, the volume of emissions will be lower (due to lower consumption) so the government will have to remunerate lower level of emission reduction (resp. gets a lower remuneration) $\left(-x Q^{\prime}(p)\left(p_{s}-p\right)\right)$.
} 
contracts $\left(\left|p^{c c^{\prime}}(x)\right|<\left|p^{\prime}(x)\right|\right)$. It is important to notice that these results hold for a given level of investment, while the equilibrium levels, as shown below, are different.

Finally, as straightforward, the government optimally increases the price to reduce (resp. increase) the differential to pay to the firm (resp. to be paid by the firm) when the strike price increases $\left(p^{c c^{\prime}}\left(p_{s}\right) \geq 0\right)$.

The problem of the firm now only depends on the strike price, as follows:

$$
\max _{x} \quad \Pi^{c c}=x p_{s}-C(x)
$$

Lemma 7. The investment problem of the firm has an unique solution, denoted as $x^{c c}\left(p_{s}\right)$ and characterized by

$$
p_{s}-C^{\prime}(x)=0
$$

and such that i) $\forall p_{s}>0, x^{c c}\left(p_{s}\right)>0$; ii) $x^{c c}(0)=0$; iii) $\forall p_{s} \geq 0, x^{c c^{\prime}}\left(p_{s}\right)>0$ and $x^{c c^{\prime \prime}}\left(p_{s}\right)<0$; and iv) $\lim _{p_{s} \rightarrow \infty} x^{c c}\left(p_{s}\right)=1$.

We denote the equilibrium price as $p^{c c}=p\left(x^{c c}\right)$.

It is straightforward to check that if the strike price is not too small, carbon contracts bring an improvement with respect to the case with no additional policies, as summarized in the following proposition.

Proposition 2 (Regulatory solution with carbon contracts). When the government cannot commit to carbon pricing, provided the strike price $p_{s}$ is not too low $\left(p_{s}>p_{s}\right)$, carbon contracts increase incentives for decarbonization $\left(x^{c c}>x^{n c}\right)$. The investment level approaches the commitment benchmark level $x^{c b}$ when the strike price $p_{s}$ approaches the commitment benchmark price level $p^{c b}$.

Under carbon contracts the firm investment is remunerated by the strike price, so the firm can no longer strategically influence carbon pricing decisions and withhold investment against rent expropriation. As long as the strike price is not too low, the investment level is higher than in the case without contracts. The level approaches the commitment benchmark level when the strike price approaches the commitment benchmark price level, as shown in Figure 1, which displays the equilibrium level of investment as a function of $p_{s}$.

Figure 2 shows the equilibrium level of carbon price $p^{c c}$ as a function of $p_{s}$, suggesting that the equilibrium carbon price is not monotonic in the strike price. In the following,

\footnotetext{
${ }^{12}$ The following functional forms are used: $C(x)=\frac{2 x}{1-x}+\frac{x^{2}}{(1-x)^{2}}$ and $Q\left(p_{G}\right)=p_{G}^{-\epsilon}$, with $\epsilon=0.6$
} 


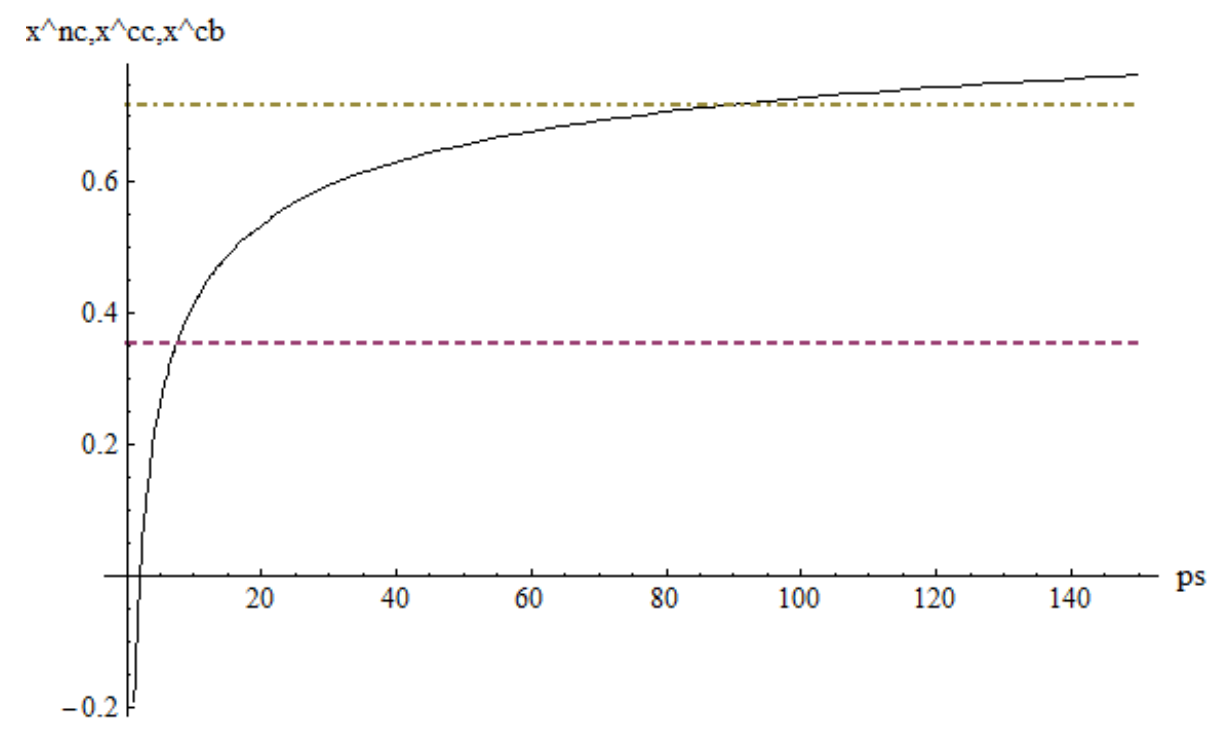

Figure 1: Optimal investment levels as a function of $p_{s}\left(x^{c c}\right.$ in black, $x^{n c}$ in dashed and $x^{c b}$ in dot-dashed) for $d=200, c=0 .{ }^{12}$

we prove and explain this result, which also guarantees that for large enough values of the strike price, also the carbon price level is larger than in the case without contracts.

Lemma 8. The effect of an increase in the strike price $p_{s}$ on optimal carbon price level $p^{c c}$ can be decomposed as follows:

$$
\frac{d p^{c c}}{d p_{s}}=\frac{\partial p}{\partial x} \frac{\partial x}{\partial p_{s}}+\frac{\partial p}{\partial p_{s}}
$$

- direct "financial" effect: $\frac{\partial p}{\partial p_{s}}>0$

- indirect "investment" effect: $\frac{\partial p}{\partial x} \frac{\partial x}{\partial p_{s}}<0$

Interpretation of Lemma 8 is that an increase in $p_{s}$ has two opposite effects on the equilibrium pricing level. On one hand, it increases the cost of remunerating investment through the contract. This increases the financial benefit from pricing, thereby encouraging higher carbon price levels: the larger $p_{s}$, the more convenient it is to increase the carbon price in order to reduce (resp. increase) the payment to (resp. from) the firm. This is the direct financial effect, which is positive (from Lemma 5 ): $\frac{\partial p}{\partial p_{s}}>0$. On the other hand, a higher strike price makes the equilibrium investment increase (from Lemma 7), $\frac{\partial x}{\partial p_{s}}>0$, which decreases equilibrium pricing (from Lemma 5 , , $\frac{\partial p}{\partial x}<0$, as government can afford lower consumption cuts. This is the indirect investment effect, which is negative. 


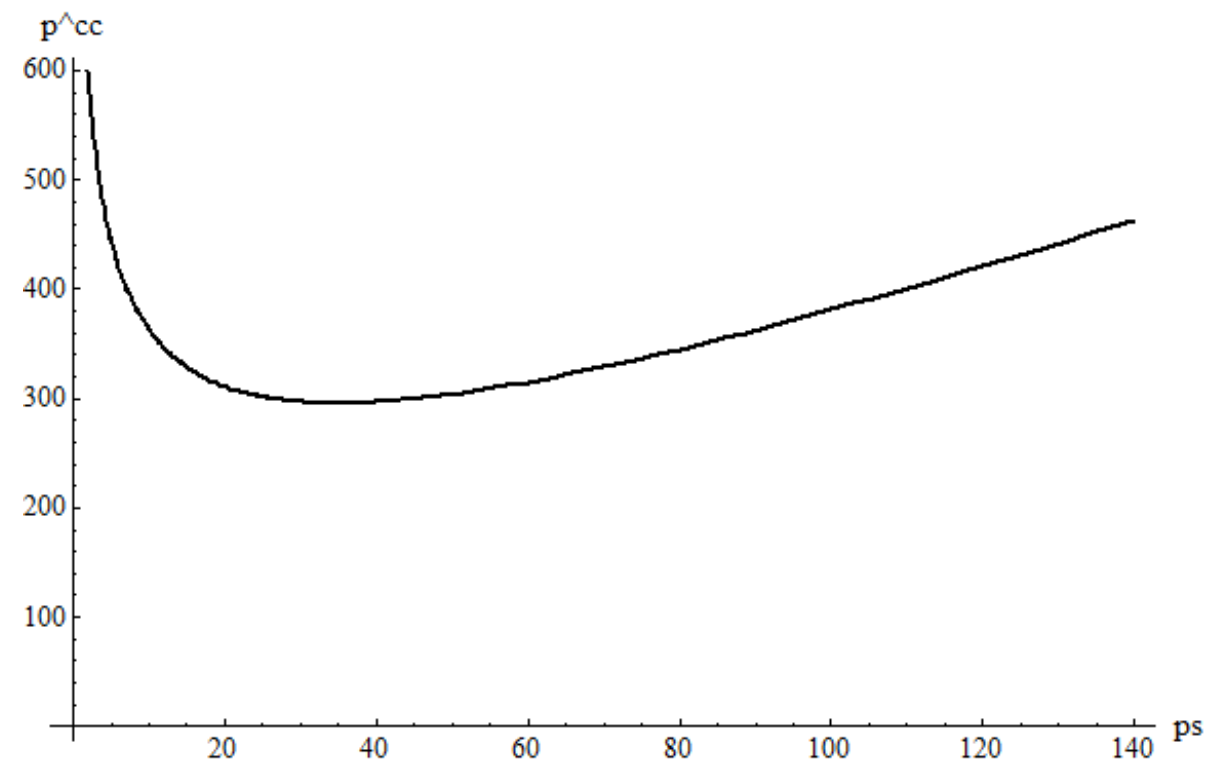

Figure 2: Optimal price level with carbon contracts as a function of $p_{s}$ for $d=200, c=0$

The sign of the overall effect is then ambiguous and depends on $p_{s}$, as characterized in the following proposition.

Proposition 3 (Non-monotonicity of the carbon price in the strike price). For small enough values of the strike price $p_{s}$, the negative investment effect dominates, so that the carbon price $p^{c c}$ decreases with the strike price $\left(\forall p_{s} \leq \hat{p}_{s}, \frac{d p^{c c}}{d p_{s}} \leq 0\right)$; otherwise the positive investment effect dominates, so that the carbon price increases with the strike price $\left(\forall p_{s}>\hat{p}_{s}, \frac{d p^{c c}}{d p_{s}}>0\right)$. Therefore, $p^{c c}$ is non-monotonic in the strike price.

The interpretation is that when the strike price is low, the financial benefit of carbon pricing is too low relative to the benefit of decarbonization triggered through larger investment, therefore the negative investment effect outweighs the positive financial effect and the equilibrium carbon pricing is decreasing in the strike price: the government cares more about containing consumer welfare costs than about the financial benefit through the contracts. When the strike price gets higher, the financial benefit of carbon pricing becomes more and more important relative to the decarbonization benefit. Once the strike price is large enough, the positive financial effect eventually dominates the negative investment effect and the equilibrium price increases: the government cares more about the financial benefit of contracts than about welfare costs.

Combining the previous results, it is possible to conclude that provided the strike price is large enough, both the investment level and the carbon price level are larger than in 
the case without contracts:

Corollary 1. $\left.\forall p_{s}>\tilde{p}_{s}>\hat{p}_{s}>\underline{p}_{s}, x^{c c}>x^{n c}, p^{c c}>p^{n c}\right)$.

Figure 2 also shows another interesting result, stated as follows:

Lemma 9. As long as the strike price is not too high $\left(p_{s} \leq d\right)$, the government finds it optimal to set a carbon price level larger than the strike price, and gains from the contracts, $p^{c c}>p_{s}$.

The intuition is that for any level of investment, the marginal benefit of cutting emissions through consumption reduction is larger than its financial cost, which calls for an increase of the optimal price above the strike price.

\section{Adoption of the carbon contracts by the govern- ment}

As a last question, it is interesting to ask whether the government is ever willing to "tie its hands" with the contracts. Namely, under which conditions the government is better off with the contracts than without.

In the current policy discourse, there are two design options about how the strike price should be determined. The former is that the contracts are auctioned and the strike price is the bid of the winning firm (lowest price wins the auction). In this case, assuming that the auction design can rule out strategic behavior on the side of the firm at the auction stage, the strike price is exogenous in the regulatory game following the auction. The latter is that the strike price is set by the government, so that it is determined endogenously in the problem. We consider both options in turn.

\section{$5.1 \quad$ Exogenous strike price}

When the government cannot optimize on the strike price level, the willingness of setting the contracts will depend on the size of $p_{s}$. It is possible to show that the result on the non-monotonicity of the carbon price transfers directly to the welfare value.

Lemma 10. The value of welfare under carbon contracts $W^{c c *}$ is non-monotonic in the strike price $p_{s}$ : 
- $\forall p_{s} \leq \hat{p}_{s}$, the indirect positive investment effect $\frac{\partial W}{\partial x} \frac{\partial x}{\partial p_{s}}$ dominates, so the overall effect is positive $\frac{d W^{c c}}{d p_{s}} \geq 0$.

- $\forall p_{s}>\hat{p}_{s}$, the direct negative financial effect $\frac{\partial W}{\partial p_{s}}<0$ dominates, so that the overall effect is negative $\frac{d W^{c c}}{d p_{s}}<0$.

The intuition is that once the carbon price level is at its optimum, an increase in the strike price has two opposite impacts on the value of welfare, similar to the impact on carbon pricing but with opposite signs. First, a direct financial effect, which is negative $\left(\frac{\partial W}{\partial p_{s}}<0\right)$ : the larger the strike price the more expensive the remuneration of emission reduction in the contract. On the other hand, there is an indirect investment effect $\left(\frac{\partial W}{\partial x} \frac{\partial x}{\partial p_{s}}\right)$ that is positive: the larger the strike price, the larger the decarbonization benefit from increased investment. Therefore, the net effect again depends on the size of $p_{s}$, such that the value function is decreasing for high enough levels of the strike price (the positive investment effect is not large enough to counterbalance the negative financial effect) and increasing otherwise (the investment effect counterbalances the negative financial effect). Therefore, as stated in the following proposition, only if the strike price is not too high, i.e. contracts are not too expensive, or not too low, i.e. still meeting the conditions of Proposition 21), is the government better off with the contracts relative to the case with no contracts and, therefore, be willing to issue them.

Proposition 4 (Exogenous strike price). If the government cannot choose the strike price, it issues the contracts if the strike price is not too low or not too high. There exists an interval $\left[\underline{p}_{s}, \bar{p}_{s}\right]$, with $\bar{p}_{s}>\hat{p}_{s}$ such that $\forall p_{s} \in\left(\underline{p}_{s}, \bar{p}_{s}\right), W^{c c *} \geq W^{n c *}$. Otherwise $W^{c c *}<W^{n c *}$.

Figure 3 gives a visualization of this result.

\subsection{Endogenous strike price}

It is straightforward that if the government is able to choose the strike price, it would choose the one that maximizes the value function i.e. that equalizes the marginal investment benefit and financial cost of the strike price highlighted before. In equilibrium, the government is always willing to set the contract. It is possible to show that the equilibrium strike price is below the commitment benchmark value:

Proposition 5 (Endogenous strike price). If the government can choose the strike price, it sets a level below the commitment benchmark $\left(p_{s}^{*}=\hat{p}_{s}<p^{c b}\right)$ and always issues the contracts in equilibrium $\left(W^{c c}\left(p_{s}^{*}\right)>W^{n c *}\right)$. 


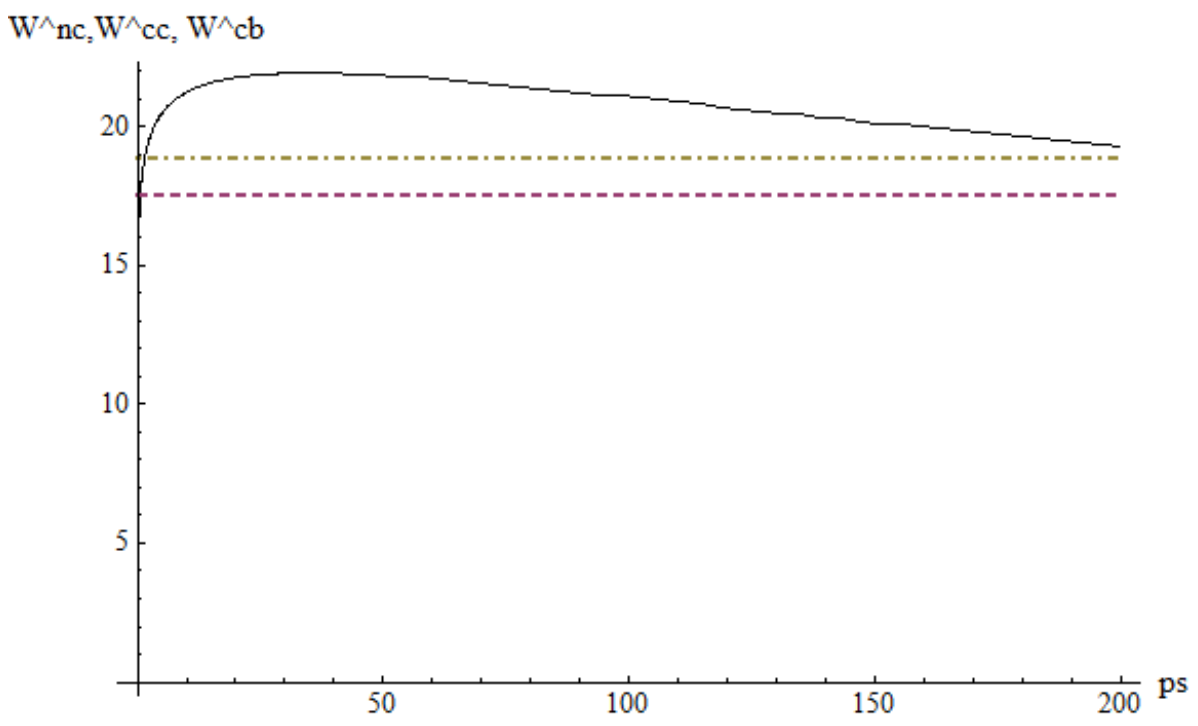

Figure 3: Value functions as a function of $p_{s}\left(W^{c c}\right.$ in black, $W^{n c}$ in dashed and $W^{c b}$ in dot-dashed) for $d=200, c=0$.

The intuition, as argued above, is that once welfare has already been optimized relative to carbon pricing decisions, an increase in price has not only a positive effect in terms of increasing investment, like in the commitment benchmark case, but also an extra negative financial effect, as given a carbon price level, the remuneration for emission reduction through the contracts is more expensive for the government, which lowers the optimal price relative to that case. This result suggests that if the government is allowed to choose the strike price, it will always "tie its hands" with the contracts in equilibrium, which means that incentives for decarbonization will be better than in the case without contracts, but the commitment benchmark levels of both price and investment would not be reached.

\section{Conclusion}

In this paper, we have provided a theoretical analysis of the problem of time-inconsistency in carbon pricing and investigated carbon contracts for differences as a solution to address the consequent hold-up problem and restore the incentive for the private sector to invest in low-carbon solutions.

We have considered a carbon regulation game between a government that takes carbon pricing decisions and a representative firm that chooses a level of investment in an 
emission-reducing technology.

Our main findings are as follows. First, stand-alone carbon pricing is prone to timeinconsistency, which leads to underpricing and underinvestment relative to the commitment benchmark. Second, when carbon pricing is complemented with carbon contracts for differences, where the government guarantees a fixed carbon price to the firm for emission reduction delivered through the investment, equilibrium levels of carbon pricing and investment are higher relative to the case without the contracts, provided the guaranteed price is high enough. Finally, when the government cannot optimize on the guaranteed price, it is willing to issue the carbon contracts if the strike price is not too high, i.e., if remuneration of investment through the contracts is not too expensive. If the government has discretion over the strike price, it always "ties its hands" in equilibrium and a welfare improvement relative to the case without additional policies is always achieved.

This work provides evidence that carbon contracts for differences can act as a credible commitment device, potentially improving on the time inconsistency problem. While in current policy discussions, carbon contracts for differences are planned to be awarded to individual investors, they can also mitigate the time-inconsistency problem for firms in the market that are not covered by the contract, as they create an incentive for the government to increase the carbon price level.

This work can be extended in many directions, including the following. First, the role of carbon contracts in the long term can be investigated, with the dynamic solution compared with the outcome of the repeated game with no additional policies. Second, the tendering and award of contracts can be included as an initial stage of the game, allowing for strategic behavior of the firm at the bidding stage. Last, the realism of the model can be increased by allowing for the technological frontier, firm risk-aversion, and information asymmetries to play a role.

\section{References}

Abrego, L. And C. Perroni (2002), "Investment subsidies and time-consistent environmental policy". Oxford Economic Papers, 54: 617-635.

BArro, R.J. (1983), "Rules, discretion and reputation in a model of monetary policy". Journal of Monetary Economics, 12(1):101-121.

Battaglini, M. And B. Harstad (2016), "Participation and Duration of Environmental Agreements". Journal of Political Economy, 124(1):160-204. 
Biglaiser, G. , Horowitz, J. And J. Quiggin (1995), "Dynamic pollution regulation". Journal of Regulatory Economics, 8:33-44.

Brunner S., and Flachsland, C. and R. Marschinski (2012), "Credible commitment in carbon policy". Climate Policy, 12(2):255-271.

CoAse, R.H. (1960), "The Problem of Social Cost". Journal of Law and Economics, $3: 1-44$.

Finus, M. And P. Pintassilgo (2013), "The role of uncertainty and learning for the success of international climate agreements ". Journal of Public Economics, 13(C):2943.

Gerlagh, R. AND M. Liski (2018), "Consistent climate policies". Journal of the European Economic Association, 16(1):1-44.

Golombeck, R., Greaker, M. and M. Hoel (2010), "Carbon Taxes and Innovation without Commitment". The B.E. Journal of Economic Analysis and Policy, 10 (1), Art. 32 .

Gersbach, H., Glazer, A. (1999), "Markets and regulatory hold-up problems". Journal of Environmental Economics and Management, 37(2):151?164.

Harstad, B., Eskeland, S. (2010), "Trading for the future: signaling in permit markets". Journal of Public Economics, 94(9-10):749-760.

Helm D., Hepburn, C. And R. Mash (2003), "Credible Carbon Policy". Oxford Review of Economic Policy, 19(3):438-450.

Helm D., Hepburn, C. And R. Mash (2004), "Time-inconsistent environmental policy and optimal delegation". Oxford University Department of Economics Discussion Paper 175 .

Helm D. And C. Hepburn (2005), "Carbon contracts and energy policy: An outline proposal". Oxford University Department of Economics Discussion Paper.

IPCC (2018), "Global Warming of 1.5C. An IPCC Special Report on the impacts of global warming of $1.5 \mathrm{C}$ above pre-industrial levels and related global greenhouse gas emission pathways, in the context of strengthening the global response to the threat of climate change, sustainable development, and efforts to eradicate poverty". Intergovernmental Panel on Climate Change. 
Ismer R. AND K. Neuhoff (2009), "Commitments through financial options: an alternative for delivering climate change obligations". Climate Policy, 9(1):9-21.

Jacob M. And S. Brunner (2014), "Optimal Commitment Under Uncertainty: Adjustment Rules for Climate Policy". Strategic Behavior and the Environment, 4:291-310.

Kalkuhl, M., Steckel, J.C. And O. Edenhofer (2020), "All or nothing: Climate policy when assets can become stranded". Journal of Environmental Economics and Management, 100:102214.

Kydland F. And E. Prescott (2004), "Rules Rather Than Discretion: The Inconsistency of Optimal Plans". Journal of Political Economy, 85(3):473-491.

Ismer, R, And K. Neuhoff (2009), "Commitments through financial options: an alternative for delivering climate change obligations". Climate Policy, 9(1):9?21.

Laffont, J.J. And J. Tirole (1996), "Pollution permits and environmental innovation". Journal of Public Economics, 62:127-140.

Laffont, J.J. And J. TiRole (1993), A theory of incentives in procurement and regulation. MIT Press.

Marsiliani, L. And T. Renström (2000), "Time inconsistency in environmental policy: tax earmarking as a commitment solution". Economic Journal, 110: C123-C138.

May, N. And O. Chiappinelli (2018), "Too Good to Be True? How Time-Inconsistent Renewable Energy Policies Can Deter Investments". DIW Discussion Paper N. 1726

May, N., Neuhoff, K. And J. Richstein (2018), "Affordable Electricity Supply via Contracts for Difference for Renewable Energy". DIW Weekly Report N. 28/2018

Montero, J.P. (1996), "A note on environmental policy and innovation when government cannot commit". Energy Economics, 33:13-19.

Neuhoff, K., Chiappinelli, O., Gerres, T., Haussner, M., Ismer, R., May, N., Pirlot, A., And J. Richstein (2019), "Building blocks for a climate-neutral European industrial sector:Policies to create markets for climate-friendly materials to boost EU global competitiveness and jobs". Climate Strategies.

Pigou, A.C. (1920), "The Economics of Welfare", London: Macmillan. 
Richstein, J.C. (2017), "Project-Based Carbon Contracts: A Way to Finance Innovative Low-Carbon Investments". DIW Discussion Paper, 1714.

Stern, N. (2007), "The Economics of Climate Change: The Stern Review", Cambridge: Cambridge University Press.

Ulph, A. And D. Ulph (2013), "Optimal Climate Change Policies When Governments Cannot Commit". Environmental and Resource Economics, 56:161-176.

Williamson, O. (1975), Markets and Hierarchies: Analysis and Antitrust Implications. New York: Free Press.

\section{Appendix}

Proof of Lemma 1. First notice that $\Pi^{c b^{\prime}}(0)=p-C^{\prime}(0)=p>0 \forall p>0$, so that $\forall p>0$, $x=0$ cannot be a solution. When $p=0, x(0)=0$. Second, $\Pi^{c b^{\prime \prime}}(x)=-C^{\prime \prime}(x)<0 \forall x \in$ $(0,1)$, so that the problem is strictly concave and the unique solution $x(p)$ is characterized by:

$$
p-C^{\prime}(x)=0
$$

From (17) it is also straightforward to check that, given assumption $\lim _{x \rightarrow 1} C^{\prime}(x)=+\infty$, it holds that $\lim _{p \rightarrow \infty} x(p)=1$. Denoting the LHS of (17) with $H$ and referring to its partial derivatives with subscripts, we have that $\forall p \geq 0$ :

$$
\begin{gathered}
x^{\prime}(p)=-\frac{H_{p}}{H_{x}}=\frac{1}{C^{\prime \prime}(x)}>0 . \\
x^{\prime \prime}(p)=\frac{\partial}{\partial p}\left[-\frac{H_{p}}{H_{x}}\right]=\frac{\partial}{\partial p}\left[\frac{1}{C^{\prime \prime}(x)}\right]=\frac{-C^{\prime \prime \prime}(x) x^{\prime}(p)}{\left[C^{\prime \prime}(x)\right]^{2}}=\frac{-C^{\prime \prime \prime}(x)}{\left[C^{\prime \prime}(x)\right]^{3}}<0 .
\end{gathered}
$$

Proof of Lemma 2. Let us write down the first and second derivative of $W^{c b}$ in (5) with respect to $p$ respectively as follows:

$W^{c b^{\prime}}(p)=p Q^{\prime}(p)+d\left[Q(p) x^{\prime}(p)-Q^{\prime}(p)(1-x(p)]+\left[Q(p)+p Q^{\prime}(p)\right](1-x(p))-p Q(p) x^{\prime}(p)\right.$ 


$$
\begin{array}{r}
W^{c b^{\prime \prime}}(p)=Q^{\prime}(p)+p Q^{\prime \prime}(p)+d\left[Q(p) x^{\prime \prime}(p)+2 Q^{\prime}(p) x^{\prime}(p)-(1-x(p)) Q^{\prime \prime}(p)\right] \\
-x^{\prime}(p)\left[Q(p)+p Q^{\prime}(p)\right]+(1-x(p))\left[2 Q^{\prime}(p)+p Q^{\prime \prime}(p)\right]-x^{\prime}(p)\left[Q(p)+p Q^{\prime}(p)\right]-p Q(p) x^{\prime \prime}(p)
\end{array}
$$

We first check that $p=0$ cannot be a solution of the problem $\left(W^{c b^{\prime}}(0)>0\right)$, and then that for positive carbon price levels the welfare function is strictly concave $\left(W^{c b^{\prime \prime}}(p)<0\right.$ $\forall p>0$ ), which implies that the interior solution is unique. Finally, we will establish the sign of $\frac{\partial p^{c b}}{\partial d}$.

It is straightforward to check that

$$
W^{c b^{\prime}}(0)=d\left[x^{\prime}(0) Q(0)-Q^{\prime}(0)\right]+Q(0)>0
$$

as $Q^{\prime}(0)<0$ and $x^{\prime}(0)>0$. On the other hand, (21) can be rewritten as

$$
\begin{aligned}
W^{c b^{\prime \prime}}(p)= & Q^{\prime}(p)+p Q^{\prime \prime}(p)+d\left[2 Q^{\prime}(p) x^{\prime}(p)-(1-x(p)) Q^{\prime \prime}(p)\right]-x^{\prime}(p)\left[Q(p)+p Q^{\prime}(p)\right] \\
& +(1-x(p))\left[2 Q^{\prime}(p)+p Q^{\prime \prime}(p)\right]-x^{\prime}(p)\left[Q(p)+p Q^{\prime}(p)\right]+(d-p) x^{\prime \prime}(p) Q(p)
\end{aligned}
$$

Notice that, by assumption: i) $Q^{\prime}(p)+p Q^{\prime \prime}(p)=S^{\prime \prime}(p) \leq 0$, which in turns implies $2 Q^{\prime}(p)+p Q^{\prime \prime}(p)<0$, ii) $Q(p)+p Q^{\prime}(p)>0$, for demand inelasticity, and iii) $d \geq p$. As in addition, $x^{\prime}(p)>0$ and $x^{\prime \prime}(p)<0$, all terms of (23) are then proved to be negative, and the welfare function to be strictly concave $\forall p>0$, implying that the interior solution is unique and is characterized by the first order condition in (6). By rewriting the latter as

$$
p Q^{\prime}(p)+d\left[Q(p) x^{\prime}(p)-Q^{\prime}(p)(1-x(p))\right]+\left[Q(p)+p Q^{\prime}(p)\right](1-x(p))-p Q(p) x^{\prime}(p)=0
$$

and denoting the LHS of (24) we have

$$
\frac{\partial p^{c b}}{\partial d}=-\frac{D_{d}}{D_{p}}
$$

Since $D_{p}<0$ for concavity, the sign of $\frac{\partial p^{c b}}{\partial d}$ is the sign of $D_{d}$

$$
D_{d}=\left[Q(p) x^{\prime}(p)-Q^{\prime}(p)(1-x(p))\right]
$$


which is positive as both terms are positive. In turn:

$$
\frac{\partial x^{c b}}{\partial d}=\frac{\partial x}{\partial p} \frac{\partial p}{\partial d}>0
$$

Proof of Lemma 3. Let us write the first and second order derivatives of $W^{n c}$ in (7) with respect to $p$ as follows:

$$
\begin{gathered}
W^{n c^{\prime}}(p)=p Q^{\prime}(p)-d Q^{\prime}(p)(1-x)+\left[Q(p)+p Q^{\prime}(p)\right](1-x) \\
W^{n c^{\prime \prime}}(p)=Q^{\prime}(p)+p Q^{\prime \prime}(p)-d Q^{\prime \prime}(p)(1-x)+\left[2 Q^{\prime}(p)+p Q^{\prime \prime}(p)\right](1-x)
\end{gathered}
$$

We proceeed as before and check first that $\forall x \in[0,1)$

$$
W^{n c^{\prime}}(0)=-d Q^{\prime}(0)(1-x)+Q(0)(1-x)>0
$$

so that $\forall x \in[0,1), p=0$ is not a solution. Second, since by assumption $Q^{\prime}(p)+$ $Q^{\prime \prime}(p) p=S^{\prime \prime}(p) \leq 0$, which also implies $2 Q^{\prime}(p)+p Q^{\prime \prime}(p)<0, W^{n c^{\prime \prime}}(p)<0 \forall p>0$, so that the interior solution is unique. From the first order condition in (8) it is also straightforward to check that $\lim _{x \rightarrow 1} p(x)=0$. Let us rewrite the first order condition (8) as

$$
p Q^{\prime}(p)-d Q^{\prime}(p)(1-x)+\left[Q(p)+p Q^{\prime}(p)\right](1-x)=0
$$

and denote the LHS of (31) as $G$. It is straightforward to check that $\forall x \in[0,1)$ :

$$
p^{\prime}(x)=-\frac{G_{x}}{G_{p}}=-\frac{d Q^{\prime}(p)-\left[Q(p)+p Q^{\prime}(p)\right]}{G_{p}}<0
$$

since $G_{p}<0$ for concavity and $G_{x}<0$ as both terms are negative (the squared parenthesis is positive for demand inelasticity).

The second derivative of the reaction function is as follows:

$$
p^{\prime \prime}(x)=\frac{\partial}{\partial x}\left[-\frac{G_{x}}{G_{p}}\right]=-\frac{\left[G_{x x}+G_{x p} p^{\prime}(x)\right] G_{p}-G_{x}\left[G_{p x}+G_{p p} p^{\prime}(x)\right]}{\left[G_{p}\right]^{2}}
$$

To determine the sign of $p^{\prime \prime}(x)$, notice the following:

- $G_{x x}=0$ 
- $G_{x p}=G_{p x}=d Q^{\prime \prime}(p)-\left[2 Q^{\prime}(p)+p Q^{\prime \prime}(p)\right]>0$, as both terms are positive by assumptions on the shape of demand and consumer welfare functions;

- $G_{p p}=\left[2 Q^{\prime \prime}(p)+p Q^{\prime \prime \prime}(p)\right]-d(1-x) Q^{\prime \prime \prime}(p)+(1-x)\left[3 Q^{\prime \prime}(p)+p Q^{\prime \prime \prime}(p)\right]>0$, as all terms are positive by assumptions on the shape of demand and consumer welfare functions;

- $p^{\prime}(x)<0, G_{x}<0, G_{p}<0$.

Let us focus on the sign of $\left[G_{p x}+G_{p p} p^{\prime}(x)\right]$, which is the sign of the following

$$
G_{p} G_{p x}-G_{p p} G_{x}=A+B+E+I+J+K+M
$$

where

$$
\begin{gathered}
A=p Q^{\prime}(p) d Q^{\prime \prime}(p)<0 \\
B=-p Q^{\prime}(p)\left[2 Q^{\prime}(p)+p Q^{\prime \prime}(p)\right]<0 \\
E=-d^{2} Q^{\prime}(p) Q^{\prime \prime}(p)(1-x)>0 \\
I=d Q^{\prime}(p)(1-x)\left[2 Q^{\prime}(p)+p Q^{\prime \prime}(p)\right]>0 \\
J=-d^{2} Q^{\prime}(p) Q^{\prime \prime}(p)>0 \\
K=2 Q^{\prime \prime}(p)\left[Q(p)+p Q^{\prime}(p)\right]>0 \\
M=d(1-x) Q^{\prime \prime}(p)\left[Q(p)+p Q^{\prime}(p)\right]-(1-x)\left[Q(p)+p Q^{\prime}(p)\right]\left[2 Q^{\prime}(p)+p Q^{\prime \prime}(p)\right] \\
-d(1-x) 3 Q^{\prime \prime}(p) Q^{\prime}(p)+(1-x) 3 Q^{\prime \prime}(p)\left[Q(p)+p Q^{\prime}(p)\right]>0
\end{gathered}
$$

It is straightforward to check that since $d \geq p, J>|A|$. In addition,

$$
\begin{array}{r}
K=2 Q^{\prime \prime}(p) Q(p)+2 Q^{\prime \prime}(p) p Q^{\prime}(p) \\
>-2 Q^{\prime \prime}(p) p Q^{\prime}(p)+2 Q^{\prime \prime}(p) p Q^{\prime}(p)=0>-p Q^{\prime}(p)\left[2 Q^{\prime}(p)+p Q^{\prime \prime}(p)\right]=B
\end{array}
$$

where the first inequality holds from inelasticity of demand. Therefore $\left[G_{p x}+G_{p p} p^{\prime}(x)\right]>$ 0 and given the sign of the other components we can conclude that the numerator of 33 ) is positive so that $p^{\prime \prime}(x)<0$ is negative on the entire domain. 
Proof of Lemma 4. We first show that $x=0$ is not a solution to the problem and that the problem is strictly concave at an internal solution, so that the internal solution is unique. By considering the first derivative of $\Pi^{n c}$ in (9)

$$
\Pi^{n c^{\prime}}(x)=p(x)+x p^{\prime}(x)-C^{\prime}(x)
$$

and evaluating it at $x=0$, we have $\Pi^{n c^{\prime}}(0)>0$, since $p(0)>0$ and $C^{\prime}(0)=0$. Therefore $x=0$ is not a solution.

$\Pi^{n c^{\prime \prime}}(x)=2 p^{\prime}(x)+x p^{\prime \prime}(x)-C^{\prime \prime}(x)<0 \forall x \in(0,1]$, since $p^{\prime}(x)<0, p^{\prime \prime}(x)<0$ and $C^{\prime \prime}(x)>0$ so the profit function is strictly concave at internal values.

Proof of Proposition 1. First notice that under commitment a change in price impacts on welfare not only directly but also through the reaction function of the firm:

$$
\frac{d W^{c b}}{d p}=\frac{\partial W}{\partial p}+\frac{\partial W}{\partial x} \frac{\partial x}{\partial p}
$$

while in absence of commitment it only has a direct effect:

$$
\frac{d W^{n c}}{d p}=\frac{\partial W}{\partial p}
$$

This implies:

$$
\frac{d W^{c b}}{d p}=\frac{d W^{n c}}{d p}+d Q(p) x^{\prime}(p)-p Q(p) x^{\prime}(p)
$$

the term $[d-p] Q(p) x^{\prime}(p)$ is positive since $x^{\prime}(p)>0$ and $d \geq p \forall p$. Therefore the optimal price of the no commitment case is suboptimal under commitment, so that $p^{c b}>p^{n c}$.

With an analogous reasoning, while under commitment a change in investment level only affects profits directly

$$
\frac{d \Pi^{c b}}{d x}=\frac{\partial \Pi}{\partial x}
$$

under commitment it impacts profits also indirectly trough the reaction function of the government

$$
\frac{d \Pi^{n c}}{d x}=\frac{\partial \Pi}{\partial x}+\frac{\partial \Pi}{\partial p} \frac{\partial p}{\partial x}
$$

which implies:

$$
\frac{d \Pi^{n c}}{d x}=\frac{d \Pi^{c b}}{d x}+x p^{\prime}(x)
$$


the term $x p^{\prime}(x)$ is negative since $p^{\prime}(x)<0$. Therefore the commitment benchmark investment level is too high under commitment, so that $x^{c b}>x^{n c}$.

As a final step we prove that the value functions of both firm and government are higher in the commitment benchmark:

$$
\Pi^{c b *}=x^{c b} p^{c b}-C\left(x^{c b}\right)>x^{n c} p^{c b}-C\left(x^{n c}\right)>x^{n c} p^{n c}-C\left(x^{n c}\right)=\Pi^{n c *}
$$

where the first inequality is given by the optimality of $x^{c b}$ under $p^{c b}$ and the second by the fact that $p^{n c}<p^{c b}$.

$$
\begin{array}{r}
W^{c b *}=S\left(p^{c b}\right)-\left(d-p^{c b}\right)\left(1-x^{c b}\right) Q\left(p^{c b}\right)>S\left(p^{n c}\right)-\left(d-p^{n c}\right)\left(1-x^{c b}\right) Q\left(p^{n c}\right) \\
>S\left(p^{n c}\right)-\left(d-p^{n c}\right)\left(1-x^{n c}\right) Q\left(p^{n c}\right)=W^{n c}
\end{array}
$$

where the first inequality is given by the optimality of $p^{c b}$ and the second by the fact that $x^{n c}<x^{c b}$.

Proof of Lemma 5. We first show that $p=0$ cannot be a solution, and then that the problem is strictly concave for positive pricing levels, so that the internal solution is unique and characterized by the first order condition in Lemma 5. Let us write the first and second derivatives of $W^{c c}$ in $(11)$ with respect to $p$ respectively as follows:

$$
W^{c c^{\prime}}(p)=p Q^{\prime}(p)-d Q^{\prime}(p)(1-x)+(1-x)\left[Q(p)+p Q^{\prime}(p)\right]+x\left[Q(p)-Q^{\prime}(p)\left(p_{s}-p\right)\right]
$$

$W^{c c^{\prime \prime}}(p)=Q^{\prime}(p)+p Q^{\prime \prime}(p)-d Q^{\prime \prime}(p)(1-x)+(1-x)\left[2 Q^{\prime}(p)+p Q^{\prime \prime}(p)\right]-x\left[Q^{\prime \prime}(p)\left(p_{s}-p\right)-2 Q^{\prime}(p)\right]$

By evaluating 52 at $p=0$ we have that $\forall x \in[0,1)$

$$
W^{c c^{\prime}}(0)=-d Q^{\prime}(0)(1-x)+(1-x) Q(0)+x\left[Q(0)-Q^{\prime}(0) p_{s}\right]>0
$$

In addition, since by assumption the term $Q^{\prime}(p)+p Q^{\prime \prime}(p)=S^{\prime \prime}(p) \leq 0$, which also implies that $\left[2 Q^{\prime}(p)+p Q^{\prime \prime}(p)\right]<0$, and the last squared parenthesis is positive, we can 
conclude that $W^{c c^{\prime \prime}}(p)<0 \forall p>0$.

From the first order condition in $(13)$ is also possible to ascertain that $\lim _{x \rightarrow 1} p^{c c}(x)=$ $\underline{p}^{c c}>0$ (as the RHS of 13 tends to a strictly positive value for $p=0$ ).

Let us rewrite the first order condition in (13) as

$$
p Q^{\prime}(p)-d Q^{\prime}(p)(1-x)+(1-x)\left[Q(p)+Q^{\prime}(p) p\right]+x\left[Q(p)-Q^{\prime}(p)\left(p_{s}-p\right)\right]=0
$$

and name the LHS as $F$. Denoting partial derivatives of $F$ with subscripts:

$$
p^{c c^{\prime}}(x)=-\frac{F_{x}}{F_{p}}=-\frac{\left(d-p_{s}\right) Q^{\prime}(p)}{F_{p}} \leq 0
$$

since $F_{p}<0$ for concavity and $F_{x} \leq 0$ given $p_{s} \leq d$.

$$
p^{c c^{\prime \prime}}(x)=\frac{\partial}{\partial x}\left[-\frac{F_{x}}{F_{p}}\right]=-\frac{\left[F_{x x}+F_{x p} p^{\prime}(x)\right] F_{p}-F_{x}\left[F_{p x}+F_{p p} p^{\prime}(x)\right]}{\left[F_{p}\right]^{2}}
$$

The sign depends on the numerator, which can be rewritten as: $F_{x x} F_{p}+p^{\prime}(x)\left[F_{x p} F_{p}-\right.$ $\left.F_{p p} F_{x}\right]-F_{x} F_{x p}$. Notice the following:

- $F_{x x}=0$

- $F_{x p}=F_{p x}=\left(d-p_{s}\right) Q^{\prime \prime}(p)>0$;

- $F_{p p}=5 Q^{\prime \prime}(p)+2 p Q^{\prime \prime \prime}(p)-d Q^{\prime \prime \prime}(p)+x Q^{\prime \prime \prime}(p)\left(d-p_{s}\right)>0$ as all terms are positive by assumptions on the shape of the demand function;

- $p^{c c^{\prime}}(x) \leq 0, F_{p}<0, F_{x}<0$.

As previously, we focus on the sign of the following:

$$
\begin{aligned}
{\left[F_{p} F_{x p}-F_{p p} F_{x}\right]=} & {\left[3 Q^{\prime}(p)+2 p Q^{\prime \prime}(p)-d Q^{\prime \prime}(p)+x Q^{\prime \prime}(p)\left(d-p_{s}\right)\right]\left(d-p_{s}\right) Q^{\prime \prime}(p)+} \\
& -\left[5 Q^{\prime \prime}(p)+2 p Q^{\prime \prime \prime}(p)-d Q^{\prime \prime \prime}(p)+x Q^{\prime \prime \prime}(p)\left(d-p_{s}\right)\right]\left(d-p_{s}\right) Q^{\prime}(p)
\end{aligned}
$$

It is possible to show that the following string of inequalities holds:

$$
\begin{array}{r}
{\left[F_{p} F_{x p}-F_{p p} F_{x}\right]<\left[-Q^{\prime \prime}(p) p-d Q^{\prime \prime}(p)+x Q^{\prime \prime}(p)\left(d-p_{s}\right)\right]\left(d-p_{s}\right) Q^{\prime \prime}(p)+} \\
{\left[Q^{\prime \prime}(p)-d Q^{\prime \prime \prime}(p)+x Q^{\prime \prime \prime}(p)\left(d-p_{s}\right)\right]\left(d-p_{s}\right) p Q^{\prime \prime}(p)=} \\
=\left[Q^{\prime \prime}(p)\left(-d+x\left(d-p_{s}\right)\right)-Q^{\prime \prime \prime}(p) p\left(-d+x\left(d-p_{s}\right)\right)\right]<0
\end{array}
$$


where the first inequality adopts the facts that $\left|Q^{\prime}(p)\right| \geq p Q^{\prime \prime}(p)$ and $2 Q^{\prime \prime}(p) \geq\left|p Q^{\prime \prime \prime}(p)\right|$ and the second the fact that $d>\left(d-p_{s}\right) x$. Therefore the numerator of (57) is proven to be positive, so that $p^{c c^{\prime \prime}}(x)$ is negative on the entire domain.

Last, $\forall x \in[0,1)$

$$
\left.p^{c c^{\prime}}\left(p_{s}\right)=\frac{\partial p}{\partial p_{s}}=-\frac{F_{p_{s}}}{F_{p}}=-\frac{-x Q^{\prime}(p)}{F_{p}}\right] \geq 0
$$

Proof of Lemma 6. By comparison of the two first order conditions of the problem of the government without and with carbon contracts, (31) and (55), the following holds:

$$
\frac{d W^{c c}}{d p}=\frac{d W^{n c}}{d p}+x\left[Q(p)-Q^{\prime}(p)\left(p_{s}-p\right)\right]>0
$$

which $\forall x \in(0,1)$ is positive as the parenthesis that multiplies $x$ is positive. This implies that for a given $x$ the optimal solution with no carbon contracts is suboptimal in the case with contracts, so that $\forall x \in(0,1) p^{c c}(x)>p(x)$. For $x=0, p^{c c}(x)=p(x)$.

To show that $\left|p^{c c^{\prime}}(x)\right|<\left|p^{\prime}(x)\right| \forall x \in[0,1)$, consider the absolute values of (32) and (56) as

$$
\begin{gathered}
\left|p^{\prime}(x)\right|=-\frac{Q(p)-(d-p) Q^{\prime}(p)}{G_{p}} \\
\left|p^{c c^{\prime}}(x)\right|=-\frac{-\left(d-p_{s}\right) Q^{\prime}(p)}{F_{p}}
\end{gathered}
$$

By indicating with $N($.$) and D($.$) respectively the numerator and the denominator$ of both (62) and (63), it is possible to check that the following holds. First, as $Q(p)-$ $(d-p) Q^{\prime}(p)>-\left(d-p_{s}\right) Q^{\prime}(p), N\left(\left|p^{\prime}(x)\right|>N\left(\left|p^{c c^{\prime}}(x)\right|\right)\right.$. Second, $F_{p}=G_{p}-x\left[Q^{\prime \prime}(p) p_{s}-\right.$ $\left.Q^{\prime \prime}(p) p-2 Q^{\prime}(p)\right]<G_{p}$ as and the squared parenthesis is positive (by assumption), so that $-F_{p}>-G_{p}$, which makes $D\left(\left|p^{\prime}(x)\right|<D\left(\left|p^{c c^{\prime}}(x)\right|\right)\right.$. Therefore, we can conclude that $\left|p^{c c^{\prime}}(x)\right|<\left|p^{\prime}(x)\right| \forall x \in[0,1)$.

Proof of Lemma 7. Notice that $\Pi^{c c^{\prime}}(0)=p_{s}-C^{\prime}(0)>0$, so $x=0$ cannot be a solution $\forall p_{s}>0$. Furthermore, $\Pi^{c c^{\prime \prime}}(x)=-C^{\prime \prime}(x)<0$, so the problem of the firm is strictly concave. By denoting the LHS of (15) with $L$, it is straightforward to check that $\forall p_{s} \geq 0$ : 


$$
\begin{gathered}
x^{c c^{\prime}}\left(p_{s}\right)=\frac{\partial x}{\partial p_{s}}=-\frac{L_{p_{s}}}{L_{x}}=-\frac{1}{-C^{\prime \prime}(x)}>0 \\
x^{c c^{\prime \prime}}\left(p_{s}\right)=\frac{\partial}{\partial p_{s}}\left[-\frac{L_{p_{s}}}{L_{x}}\right]=\frac{\partial}{\partial p_{s}}\left[\frac{1}{C^{\prime \prime}(x)}\right]=\frac{-C^{\prime \prime \prime}(x) x^{\prime}(p)}{\left[C^{\prime \prime}(x)\right]^{2}}=\frac{-C^{\prime \prime \prime}(x)}{\left[C^{\prime \prime}(x)\right]^{3}}<0
\end{gathered}
$$

Proof of Proposition 2. By comparing the two first order conditions of the problem of the firm with and without the contracts

$$
\begin{gathered}
\frac{d \Pi^{n c}}{d x}=p^{\prime}(x) x+p(x)-C^{\prime}(x) \\
\frac{d \Pi^{c c}}{d x}=p_{s}-C^{\prime}(x)
\end{gathered}
$$

it is possible to write

$$
\frac{d \Pi^{n c}}{d x}=\frac{d \Pi^{c c}}{d x}-p_{s}+p^{\prime}(x) x+p(x)
$$

so that if $p_{s}$ is large enough $p_{s}>p_{s}$, where $\underline{p_{s}}=p^{\prime}(x) x+p(x)\left(p^{\prime}(x)<0\right)$, then $\frac{d \Pi^{n c}}{d x}<0$ meaning that the optimal level of investment with contracts is too high in absence of contracts, implying $x^{c c}>x^{n c}$.

Proof of Proposition 3. By using the expressions for the partial derivatives in Lemmas 5 and 7 the total effect in equation (16) can be re-written as:

$$
\frac{d p^{c c}}{d p_{s}}=\left(-\frac{F_{x}}{F_{p}}\right)\left(-\frac{L_{p_{s}}}{L_{x}}\right)+\left(-\frac{F_{p_{s}}}{F_{p}}\right)=-\frac{1}{F_{p}}\left[F_{x}\left(-\frac{L_{p_{s}}}{L_{x}}\right)+F_{p_{s}}\right]
$$

Since $-\frac{1}{F_{p}}>0$ (from concavity $F_{p}<0$ ), the sign of $\frac{d p^{c c}}{d p_{s}}$ is the sign of the expression in the squared parentheses. It is straightforward to check that

$$
\left[F_{x}\left(-\frac{L_{p_{s}}}{L_{x}}\right)+F_{p_{s}}\right]=x^{\prime}\left(p_{s}\right)\left(d-p_{s}\right) Q^{\prime}(p)-x\left(p_{s}\right) Q^{\prime}(p)
$$

Since $-Q^{\prime}(p)>0$ the sign of the expression therefore depends on the sign of

$$
A\left(p_{s}\right)=-x^{\prime}\left(p_{s}\right)\left(d-p_{s}\right)+x\left(p_{s}\right)
$$


We can study how $A\left(p_{s}\right)$ varies with respect to $p_{s}$, and we have that given $d \geq p_{s}$ and $x^{\prime}\left(p_{s}\right)>0, x^{\prime \prime}\left(p_{s}\right)<0$

$$
A^{\prime}\left(p_{s}\right)=-x^{\prime \prime}\left(p_{s}\right)\left(d-p_{s}\right)+2 x^{\prime}\left(p_{s}\right)>0
$$

As furthermore, $A(0)=-x^{\prime}(0) d<0$, since $x^{\prime}(0)>0$ and $x(0)=0$, we can conclude that there exists a value of $p_{s}, \hat{p}_{s} \in\left(0, p_{s}^{\max }\right)$ such that for $p_{s} \leq \hat{p}_{s}, A\left(p_{s}\right) \leq 0$ and $\frac{\partial p^{c c}}{\partial p_{s}} \leq 0$, while for $p_{s}>\hat{p}_{s}, A\left(p_{s}\right)>0$, and $\frac{\partial p^{c c}}{\partial p_{s}}>0$.

Proof of Corollarly 1. As $p^{n c}$ is constant relative to $p_{s}$ and we know from Proposition 2 that for $p_{s}=\underline{p_{s}}>0, x^{c c}=x^{n c}>0$, and from Lemma 6 that for a given $x>0 p^{c c}>p^{n c}$, we can conclude that there is an interval $\left(\underline{p_{s}}, \tilde{p_{s}}\right)$, with $\tilde{p_{s}}>\hat{p_{s}}$, such that $\forall p_{s} \leq \underline{p_{s}}$ and $\forall p_{s}>\tilde{p}_{s}, p^{c c}>p^{n c}$. This implies that for large enough values of $p_{s}\left(p_{s}>\tilde{p}_{s}\right)$ both the investment level and the carbon price level are larger than in the case without contracts.

Proof of Lemma 9. By considering that a reduction in revenues due to investment $(-x[Q(p)+$ $\left.\left.Q^{\prime}(p) p\right]\right)$ is perfectly compensated by an increase in payment from carbon contracts $(+x[Q(p)+$ $\left.\left.Q^{\prime}(p) p\right]\right)$, the first order condition in 13 can be simplified and rearranged to

$$
p Q^{\prime}(p)-d Q^{\prime}(p)+x Q^{\prime}(p)\left[d-p_{s}\right]+\left[Q(p)+Q^{\prime}(p) p\right]=0
$$

Evaluating the LHS of (73) at $p_{s}$ we obtain the following

$$
Q\left(p_{s}\right)+Q^{\prime}\left(p_{s}\right) p_{s}-\left(d-p_{s}\right)(1-x) Q^{\prime}\left(p_{s}\right)
$$

The term $Q\left(p_{s}\right)+p_{s} Q^{\prime}\left(p_{s}\right)$ is positive, and $\forall p_{s} \leq d$ also the latter is, so that (74) is positive, and therefore $p^{c c}>p_{s}$.

Proof of Lemma 10. The effect of $p_{s}$ on $W^{c c *}$ is as follows

$$
\frac{\left.d W^{c c}\left(p\left(x\left(p_{s}\right)\right), x\left(p_{s}\right), p_{s}\right)\right)}{d p_{s}}=\frac{\partial W^{c c}}{\partial p} \frac{\partial p}{\partial x} \frac{\partial x}{\partial p_{s}}+\frac{\partial W^{c c}}{\partial x} \frac{\partial x}{\partial p_{s}}+\frac{\partial W^{c c}}{\partial p_{s}}
$$

Noticing that the first term is equal to zero for the envelope theorem, while $\frac{\partial W}{\partial x}=(d-$ $\left.p_{s}\right) Q(p)$ and $\frac{\partial W}{\partial p_{s}}=-x Q(p)$, we have

$$
\frac{d W^{c c}}{d p_{s}}=\left(d-p_{s}\right) Q(p) x^{\prime}\left(p_{s}\right)-x Q(p)
$$


Therefore the sign of $\frac{d W^{c c}}{d p_{s}}$ is the sign of

$$
B\left(p_{s}\right)=\left(d-p_{s}\right) x^{\prime}\left(p_{s}\right)-x\left(p_{s}\right)
$$

It is straightforward to check that $B\left(p_{s}\right)=-A\left(p_{s}\right)$, so that the behavior of the sign of $\frac{d W^{c c}}{d p_{s}}$ is the opposite of $\frac{d p^{c c}}{d p_{s}}$, namely: given $p_{s} \leq d, B\left(p_{s}\right)>0$ and $\frac{d W^{c c}}{d p_{s}} \geq 0$ if $p_{s} \leq \hat{p_{s}}$ while if $p_{s}>\hat{p}_{s}, B\left(p_{s}\right)<0$ and $\frac{d W^{c c}}{d p_{s}}<0$.

Proof of Proposition 4. The government is going to introduce carbon contracts if $W^{c c *}>$ $W^{n c *}$, where $W^{c c *}$ and $W^{n c *}$ are the value functions in the case with and without contracts, respectively. Since $W^{n c *}$ is constant with respect to $p_{s}$ and $W^{c c *}$ increasing in $p_{s}$ until a given threshold $\hat{p}_{s}$ and then decreasing, if we show that $W^{c c}\left(p_{s}=p_{s}\right) \geq W^{n c}$, then we know that there is a range of values of $p_{s},\left[\underline{p_{s}}, \overline{p_{s}}\right]$, where $\underline{p_{s}}<\hat{p}_{s}<\overline{p_{s}}$, such that $\forall p_{s} \in\left(\underline{p_{s}}, \overline{p_{s}}\right), W^{c c *}>W^{n c *}$.

From Proposition 2 we have that for $p_{s}=\underline{p_{s}}, x^{c c}=x^{n c}$, and from Lemma 6 that $p^{c c}(x) \geq p(x) \forall x \in[0,1)$, so that the following string of inequalities hold:

$$
\begin{aligned}
W^{c c}\left(p_{s}=\underline{p_{s}}\right)= & \\
& S\left(p^{c c}\right)-d Q\left(p^{c c}\right)\left(1-x^{n c}\right)+p^{c c} Q\left(p^{c c}\right)\left(1-x^{n c}\right)+x^{n c} Q\left(p^{c c}\right)\left(p^{c c}-\underline{p_{s}}\right) \\
& >S\left(p^{n c}\right)-d Q\left(p^{n c}\right)\left(1-x^{n c}\right)+p^{n c} Q\left(p^{n c}\right)\left(1-x^{n c}\right)+x^{n c} Q\left(p^{c c}\right)\left(p^{c c}-\underline{p_{s}}\right) \\
& >S\left(p^{n c}\right)-\left(d-p^{n c}\right) Q\left(p^{n c}\right)\left(1-x^{n c}\right)=W^{n c}
\end{aligned}
$$

where the first inequality is given by the fact that $p^{c c}$ maximizes $W^{c c}$ and the second one by the fact that $p^{c c}>p_{s} \forall p_{s} \leq d$ (from Lemma 9) so that the government gains from the contracts in equilibrium.

Proof of Lemma 5. By comparison of the two expressions of a marginal change in carbon price in the commitment benchmark case (44) and in the case of carbon contract with endogenous strike price 75 and considering that $\frac{\partial W^{c c}}{\partial p}=0$ because of the envelope theorem, we get the following

$$
\frac{d W^{c b}}{d p}=\frac{d W^{c c}}{d p}+\left[p Q^{\prime}(p)+Q(p)\right]-(d-p)[1-x(p)] Q^{\prime}(p)
$$

As the second and third term on the RHS of (78) are positive, it is possible to conclude that the optimal price level under the contract is suboptimal in the commitment benchmark, 
so that $p^{c b}>p_{s}^{*}$. 